in the manner already described for the surface potential method, but lines of equal magnetic intensity and iso-phase lines may also be drawn.

The method described above resembles the two-coil balancing system due to Sundberg and Lundberg, in which two similar coils are joined in opposition, with an amplifier and telephone included in the circuit. In this case the relative strengths of the vertical fields are given by the secant of the angle through which one of the coils must be tilted out of the horizontal in order to produce a minimum of sound in the telephone. It has been pointed out by Eve and Keys,* that this procedure is not always satisfactory owing to phase difference in the currents induced in the two coils, and the fact that the tilting of one of the coils will usually introduce a horizontal component into the determination. These writers actually suggest a capacitance bridge in this connexion, but fear that such an instrument would prove too cumbersome for use under ordinary field conditions.

* “Applied Geophysics”, p. 122 (University Press, Cambridge, 1929).

\title{
Nomenclature at the Eleventh International Zoological Congress.
}

THE account of the International Congress of 1 Zoologists at Padua, published in Nature for Sept. 27, 1930 (pages 489-490), contained only the briefest reference to the discussions and conclusions on nomenclature. The following account, which is strictly unofficial, may be of interest.

The International Commission on Zoological Nomenclature consists of eighteen members, distributed so far as is practically convenient throughout the world. Most of its work is conducted by correspondence, the intermediary being the secretary. The present secretary is in Washington and is permitted by the U.S. Government to avail himself of official facilities.

The commissioners meet in person at the International Congresses of Zoologists, which hitherto have been triennial, except for an interval from 1913 (Monaco) to 1927 (Budapest), but which by a resolution at Padua are henceforward to be quinquennial. Hitherto each commissioner has been appointed for the triennial period ; whether this will now be changed for a quinquennial period remains to be seen.

Certain changes in the mode of appointment were accepted by the Padua Congress. To replace the retiring commissioners, who are eligible for reappointment, the Commission, after considering the balance of subjects and of geographical regions, submits names to the Section of Nomenclature. The Section can propose other names. The nominees of both Commission and Section are referred to the Permanent Committee of the Congress, which makes the selection and reports it to the plenum of the Congress for confirmation.

The commissioners assemble a week before the Congress opens, and work all day and every day at final discussion and voting on the questions raised during the interval. These may be either opinions on points of nomenclature or proposals for alteration of the rules.

Opinions are settled by a majority vote of the Commission, and this is generally obtained by correspondence.

Proposed changes in the rules must also have received a preliminary majority vote of the whole Commission, that is, ten out of eighteen, and must then receive the unanimous vote of those present at the Congress, nine being a quorum. It follows that, on one hand, eight commissioners may have opposed a proposal in writing, but that nine present in person may carry it ; and on the other hand, that seventeen may have been in favour, but that one if present may block it. These are extreme suppositions, but in actual practice the situation is no better, because of the difficulty of bringing all the members together, or even of obtaining a quorum of the actual commissioners. To overcome this difficulty it has been the custom to appoint substitutes (alternates). for the absent commissioners from among zoologists attending the Congress. Thus many of those who actually vote may have an imperfect understanding of the questions at issue. At Padua the preliminary work was done by the chairman (K. Jordan), the secretary (C. W. Stiles), and three other commissioners ; two more commissioners arrived later, but a quorum was not formed until alternates were appointed. Of these there were no less than eleven, and among them Lt.-Col. J. Stephenson, Mr. G. C. Robson, and Mr. H. W. Parker acted for commissioners in various parts of the British Empire.

On this occasion a further difficulty was due to the fact that before the meeting none of the proposals for change in the rules had received enough votes either to kill it or to bring it up for discussion. Until the Congress assembled it was impossible to get the necessary votes, and then, even if they were obtained, it was too late for adequate and properly informed discussion.

This state of affairs is manifestly undesirable, and for many years considerable dissatisfaction with these arrangements has been expressed, notably with the demand for a unanimous vote by those present. There were two alternative amendments to this bylaw before the Commission, but unfortunately neither received enough preliminary votes to enable it to be discussed.

The same was the fate of other important proposals. Among them were alternative motions which would have had the effect of raising type-designation by elimination from the status of a recommendation to the status of a rule. This is a difficult question, and it is a pity that it could not be thrashed out.

A proposal to revert to the XII. Edition of Linnæus" "Systema Naturæ" as the starting-point of zoological nomenclature was definitely rejected, and the date of the $\mathbf{X}$. Edition was fixed precisely as Jan. 1, 1758, in Article 26 of the rules.

The definition of publication for purposes of systematic zoology was discussed at length, and the conclusions will eventually be submitted in the form of an opinion.

The report of the British National Committee on Entomological Nomenclature was presented by Dr. K. Jordan, and its proposed emendations to the rules were considered. A few, of merely editorial nature, were provisionally adopted and others deferred for further consideration.

Proposals that superfamily names based on generic names should all end in -oidea, that new ordinal names should ond in ida, and subordinal names in ina were discussed and held for further consideration.

Proposals to apply the law of priority to family and subfamily names, under certain conditions necessitated by other provisions of the Code, were also inevitably held over. The general opinion of the Commission seemed to be against further legislation for groups higher than genera.

As regards homonyms, it was agreed that, ceteris

No. 3192, VoL. 127] 
paribus, the name of a genus should take precedence over that of a subgenus; the name of a species over that of a subspecies.

Article 19 of the rules says that "the original orthography of a name is to be preserved unless an error of transcription, a lapsus calami, or a typographical error is evident". It was agreed that the word "transcription" included, or rather was intended to mean, "transliteration". This article has sometimes important results in connexion with homonyms. Concerning such trivialities as whether one should write brownii or browni, the Commission showed a wise impatience. It also agreed that when a name, or part of a name in combination, had been spelled in diverse ways by different authors or even by the same author, it was not incumbent on a subsequent author, when making casual references, to follow this diversity of spelling. It was enough that he should do so in professed synonymic lists.

During the interval between the tenth and eleventh Congresses the Commission had formulated twentysix opinions (Nos. 98-123), and these were adopted by the Congress. These opinions have been or are being published by the Smithsonian Institution.

The Commission would welcome the co-operation of special committees for groups of animals. Such co-operation already exists for entomology and proves of great advantage.

The Commission believes that much confusion would be avoided if students of zoology had the opportunity -if not the obligation-to attend lectures on the rules of nomenclature.

I have kept to the last the most controversial of the subjects that came up at Padua. This is the interpretation of Article 25b of the Code. It is there laid down that "The valid name of a genus or species can be only that name under which it was first designated on the condition . . . (b). That the author has applied the principles of binary nomenclature". Article 26 says: "The tenth Edition of Linné's 'Systema Naturæ', 1758, is the work which inaugurated the consistent general application of the binary nomenclature in zoology".

The question in dispute is the meaning of the phrase "binary nomenclature". One interpretation is that it means that form of zoological nomenclature which most zoologists associate with Linnæus and notably with the tenth edition of his "Systema", namely, one name for the genus, with which is associated another, so-called trivial name, to make up the nomen specificum. The addition of a third name to distinguish a subspecies, or even of a fourth for avariety, does not affect the principle that the species is designated by a double or binary name. The essence of the Linnean reform, as first fully expressed in the Tenth Edition, is the introduction of a nomen triviale in place of the former differentia; the nomen triviale being a pure name, not necessarily with any meaning, whereas the differentia was a descriptive diagnostic phrase, however short it might be.

The other interpretation of " binary nomenclature" reduces it to mean no more than ' binary classification'; in other words, the recognition of the two concepts genus and species, and their nomenclature, according to the old logical method, per genus et differentiam.

The introduction of this latter method into systematic biology is ascribed to the botanist Tournefort (1719). The method was at first followed by Linnæus as by many others, but he perceived its nomenclatural cumbrousness (as indeed had Tournefort himself) and got over the difficulty by using the nomen triviale in place of the differentia. This he essayed before 1758, but it was in that year, in the Tenth Edition, that he first applied it consistently to the whole animal kingdom.
Taking the rules as they stand, any unsophisticated zoologist would, I think, adopt the former interpretation. In the successive reports of the Congress and successive editions of the rules I have been unable to find anything that suggests the contrary, with the exception of four opinions $(20,24,35,89)$. These draw a distinction between the terms 'binary' and 'binominal' (undoubtedly they do not mean the same thing) and proceed to imply that 'binary' indicates nomenclature à la Tournefort, while only 'binominal ' indicates nomenclature à la Linné.

The history of this interpretation of the phrase 'binary nomenclature' has been given by Dr. L. Stejneger in a most careful paper (Smithson Miscell. Coll., vol. 77, No. 1, August 1924), which leaves no doubt that the revisers of the Code in 1901 really did give the phrase what one may call the Tournefort sense, and that their reason for that interpretation was the desire to include the generic names of Brisson, L. T. Gronovius, Scopoli, and other writers after 1758 who did not follow the nomenclatural system of Linnæus, and to include them without making exceptions to the rules.

That this was their intention was, as Dr. Stejneger himself admits, far from obvious, and it certainly has never been clear to a large number of zoologists. However that may be, there has been an increasing movement to give the phrase the same meaning as the tautological expression "binominal nomenclature". A proposal to that effect was before the Commission at Padua, but failed to receive enough preliminary votes to bring it up for discussion. In the Section of Nomenclature, Dr. Walther Horn then proposed the following motion: "The Congress shall decide that only those publications shall be held to apply the principles of binary nomenclature in which the use of a single word for a generic name and a single word for a species name is consistently carried out". This was passed by a large majority in the Section, and when it came before the plenary session of the Congress, instead of being referred, as one expected, to the Commission, it was put to the meeting without discussion, and again carried by a large majority.

It happens, most unfortunately, that those who support what I have called the Tournefort interpretation are for the most part citizens of the United States and include the distinguished and enthusiastic secretary of the Commission, whereas most of those who support the Linnean interpretation come from the rest of the world and in great part from Europe. I do not, however, see any reason why this divergence of opinion cannot be accommodated. The resolution does not, in my opinion, involve any alteration of the rules; it is a question of interpretation. It does involve a redrafting of certain opinions, but it need not involve any change in their effect or in the acceptance of Brisson and the rest.

It should be remembered that in 1901 it was not possible to suspend the rules to meet hard cases. That practical reform was first achieved at Monaco in 1913. Therefore in 1901 the upholders of Brisson, Scopoli, and Co. were obliged either to alter the rules or to interpret them so as to admit those authors. They inadvisedly adopted the latter course and failed. to make it clear.

Their interpretation has been used, as stated above, to admit the uninominal generic names of certain writers after 1758 who did not follow the Linnean method. But those writers did occasionally chance to use a specific differentia of a single word, and, on this interpretation, there seems nothing to prevent the admission of those appellations. That, however, does not seem desired by anyone.

Now we can suspend the rules, and we have already 
found it necessary to do so in order to eliminate certain authors who, under the Tournefort interpretation, were admissible (opinion 89).

My proposal therefore is that we should, as the Congress has resolved, adopt the Linnean interpretation, which I personally believe to be the natural meaning of the words ; that we should formulate a new opinion admitting the generic names of Brisson and the rest by ad hoc suspension of Article 25b; and that we should redraft those opinions that are affected (20 and 24). As for opinion 89, I succeeded at the time in getting it so drafted that its effect would not be altered by the change of interpretation now passed by the Congress.

If these proposals are approved by the International Commission, I do not see why we should not continue to work with that harmony and good feeling which have hitherto prevailed at our meetings.

\section{F. A. Bather.}

\section{University and Educational Intelligence.}

Cambridae,-Prof. Owen Thomas Jones, Woodwardian professor of geology, has been elected to a professorial fellowship at Clare College.

At Trinity College, A. S. Besicovitch, University lecturer in mathematics, and $\mathrm{L}$. Wittgenstein have been elected to fellowships.

The Appointments Committee of the Faculty of Geography has reappointed Miss M. S. Willis, of Newnham College, to be University demonstrator in the Faculty.

The Council of the Senate recommends the acceptance of the offer of the Council of the Royal Society to provide within three years a sum of $£ 15,000$ towards the building and equipment of a Laboratory for special physical investigations in the University of Cambridge, to be used in the first instance for magnetic and crvogenic research.

LONDON.-The title of emeritus professor has been conferred on Dr. Alice Werner, formerly University professor of Swahili and the Bantu languages at the School of Oriental Studies.

On the recommendation of the Board of Management of the London School of Hygiene and Tropical Medicine, Sir George Newman has been appointed Heath Clark Lecturer for the year 1931.

Oxford.-Prof. A. Einstein will deliver the Rhodes Memorial Lecture for the year 1930-31; he will be in residence in Oxford during the next summer term.

ST. Andrews.-On the recommendation of the Senatus Academicus, the Court on Dec. 19 unanimously agreed to appoint Dr. David Lennox to be reader in forensic medicine, and Dr. W. L. Burgess to be reader in public health, in recognition of their long and distinguished service to the University as lecturers in these subjects.

Mr. George H. S. Milln was appointed lecturer in radiology and electrical therapeutics in the University, and Dr. David Jack to be a lecturer in natural philosophy in the United College, St. Andrews.

The Senatus Academicus has appointed Dr. R. R. Marett, Rector of Exeter College, Oxford, as Gifford Lecturer for 193I-32.

It was reported that the last Examination for the diploma and title of L.L.A. will be held in May next. The only candidates to be received are those who have already obtained part of the qualification and desire to complete it.

\section{Birthdays and Research Centres.}

Jan. I, 1869.-Prof. A. A. T. Brachet, For.Mem.R.S., Rector of the University of Brussels and director of the Laboratory of Embryology of the Faculty of Medicine in the University.

Le laboratoire d'Embryologie de la Faculté de médecine de Bruxelles suit principalement deux lignes de recherches: D'une part, l'analyse des localisations germinales et du déterminisme de la morphogénèse chez les Vertébrés, spécialement les Amphibiens; d'autre part, l'étude de la physiologie de la mise en marche du développement et des cinèses de segmentation.

Jan. 7, r885.--Prof. A. J. Allumand, F.R.S., professor of chemistry, King's College, London.

The chemical laboratory at King's College is a comparatively small one, and the conditions, therefore, unfavourable for directed team-work research towards pre-specified major objectives. But I believe firmly that almost any subject, if worked on pertinaciously and with reasonable skill, conscientiously (that is, with self-criticism), and with the desire for early publication strictly suppressed, may yield at any time results of real interest, even of importance. On this account, I would hesitate to say which I consider the chief investigation now in progress in this laboratory.

My students are working (1) at photochemistry, particularly at present on the effect of wave-length on the union of hydrogen and chlorine, as also on other reactions; (2) on the problem of the complete evaluation of the partial molal free energies in systems of the type lead chloride-alkali metal chloride-water; (3) on the sorption of vapours and gases by charcoal and other solid sorbents.

These investigations have all been in progress for years and have all proved sufficiently fruitful to satisfy us.

Jan. 8, I 856.-Prof. H. Lecomte, professor of botany in the Paris Museum of Natural History.

Since his appointment to the professorship of botany in the Paris Museum, Prof. Lecomte has directed the work of the staff definitely to the study of Colonial floras, which were known before only in a fragmentary way. The "Flore Générale de IIndoChine" was the first undertaken (1906); forty-four parts, out of about fifty it will comprise, have been already completed, with the devoted assistance of the scientific staff, of many Parisian botanists frequenting the Laboratory, and of professors from Paris and provincial universities. Besides, a great quantity of working material has been assembled and is ready to study for the preparation of floras of other French colonies : Guiana, Antilles, tropical Africa, Madagasear, New Caledonia. For some years past, and to complete this work, Prof. Lecomte has undertaken the anatomical study of tropical woods, of great interest from the point of view of the affinities it reveals, and also for the applications it enables one to foresee. Two important books have been published on woods of Indo-China and Madagascar.

Jan. 8, r 868. - Sir Frank W. Dyson, K.B.E., F.R.S., Astronomer-Royal.

A problem to which attention might usefully be given is the determination of the radial velocities of distant stars, such as those of early B type and those with the $c$ characteristic in the southern half of the Galaxy. Dr. Oort has shown that the rotation of the system of stars round a point in galactic longitude $l_{0}$ would give rise to a term $A r \sin 2\left(l-l_{0}\right)$ in their radial 